\section{Taiwanese panel rejects spending \$64 million on SSC}

Tokyo \& Washington. In a possible setback for the US Superconducting Super Collider (SSC), Taiwan's leading science policymaking body last week voted not to participate in building one of the main detectors of the collider. But the decision by the National Science Council of Taiwan must be reviewed by the Taiwan cabinet (executive yuan), which has just been reformed following the appointment of a new premier.

On 22 February, a review panel of the council voted 12 to 4 against a proposal to spend US\$64 million in Taiwan on building the central tracking system for the $\$ 530$ million GEM (gamma rays-electronsmuons) detector, one of two planned for the collider. About $\$ 50$ million would be spent on the design, construction and assembling of the tracker and the rest on a scientific exchange programme and the purchase of equipment. The tracker would be built at Taiwan's Industrial Technology Research Institute (ITRI).

The US government is providing only about half of what is needed to build the two detectors, GEM and SDC (Solenoidal Detector Collaboration), so outside contributions are essential to their success. The SDC will cost an estimated $\$ 610$ million.

Proponents believe that participation in GEM would benefit high-energy physics in Taiwan, advance ITRI's goals of developing electronic packaging, composite materials, integrated optoelectronic circuits and communication systems and teach the institute how to integrate a complete high- technology system. Critics say that there is little new technology to be learned, that Taiwan has no infrastructure and very little experience in high energy physics and that the investment is risky because SSC officials may decide to cancel or delay GEM to save money (see below).

The council vote came one day before Taiwan's president, T.H. Lee, appointed a new premier, Chan Lien, to head the executive yuan, which must approve the council's decision. And Lien's choice to be chairman of the council, N. Kuo, supports Taiwan's participation in the SSC.

SSC officials and scientists involved in the collaboration say that they expect the new cabinet to overrule the council and reaffirm a cooperative agreement signed last November between the SSC laboratory and the Taiwanese government. The council has "flipflopped" on the SSC issue in the past, says Shih Chang Lee, deputy director of the Institute of Physics of Academia Sinica, which is one of the partners in the collaboration. Rather than either accepting or rejecting the council's recommendation, the cabinet could ask the council to reconsider the matter.

Work on the central tracking system will continue regardless of what the Taiwanese decide, according to the head of the US team, Charles Baltay of Yale University. "The collaboration has been under way for a year," he says, "and the only issue is whether they will put up big or little bucks".

David Swinbanks \& Jeffrey Mervis

\title{
SSC report finds overruns
}

Washington. A new analysis for the US Congress of the Superconducting Super Collider (SSC) has found serious cost overruns and poor management practices in the $\$ 10$ billion project. The results are disputed by the Department of Energy, which says that the report relied on outdated and inaccurate information, but it seems certain to prove useful to congressional opponents in their annual fight to terminate the programme.

The General Accounting Office (GAO) last month reported to the Committee on Science, Space and Technology of the US House of Representatives that the cost of conventional construction may exceed the $\$ 1.25$ billion estimate by half on the basis of what has been spent on the first 10 per cent of the work. The cost of making the 8,000 superconducting dipole magnets that bend the two opposing proton beams was similarly running 25 per cent above projections, the GAO reported, and SSC officials had not included the cost of storage if the magnets could not be installed promptly in the 54 mile-long tunnel being dug in Waxahachee, Texas. The problem, according to the GAO, is that the consortium of universities managing the project "still does not have a system in place that would allow it to objectively monitor the project's cost and schedule".

In a letter of 24 February to US Representative George Brown, chairman of the science committee, Energy Secretary Hazel O'Leary says that the GAO ignored relevant information and distorted spending patterns in reaching its conclusions. Although O'Leary insists that the project is on schedule for completion in 1999 for $\$ 8.25$ billion, she admits that a recent decision by President Bill Clinton to extend the programme by four years will raise the cost.

\section{UK universities get funding on basis of ranking}

London. British universities, old and 'new', are feeling the effects of a research assessment exercise carried out last year, with some reaping the rewards of a good rating and others experiencing a loss of funding for the next academic year.

Both Cambridge and Oxford, for example, which topped the league in terms of the number of high-scoring research departments, will enjoy an increase of more than 11 per cent in total public funding, including a 15 per cent increase in support for research (see table below). Those 'new' universities - previously known as poly-

\section{England's Top Ten (in $\mathbf{f}$ million)}

University of Oxford

40.63

University of Cambridge

40.04

University of Manchester

28.11

University College, London

25.68

Imperial College, London

23.56

University of Birmingham

21.22

University of Leeds

21.07

University of Liverpool

18.35

University of Nottingham

17.87

Kings College, London

14.65

technics - that did well in the assessment exercise will share $£ 36$ million (US $\$ 50$ million) for research and an additional sum for "the development of research potential".

In contrast, 'old' universities that did relatively badly in the assessment exercise, such as Aston in Birmingham, Bradford and Salford, will see their public funding reduced by one per cent.

The grants next year to 200 higher and further education institutions in England were announced last week by the Higher Education Funding Council for England (HEFCE), which has absorbed the funding responsibilities of the Universities Funding Council and the Polytechnics and Colleges Funding Council. (Separate figures will be announced later for Scotland and Wales). Overall, funding allocated for research in these institutions through the HEFCE will increase by 9 per cent, to $£ 618$ million.

The money has been distributed according to a three-part formula. Just under 95 per cent of the total - $£ 585$ million — has been allocated on the basis of their ratings (see Nature 360, 700; 1993). A further $£ 20.5$ million was distributed to universities on the basis of their success in obtaining outside contracts. The remaining $£ 12.5$ million has been distributed to 55 institutions considered capable of delivering high-quality research.

David Dickson 